\title{
La imaginación en la filosofía de Hegel
}

\author{
ALEJANDRO ROJAS JIMÉNEZ \\ Ludwing-Maximilians-Universität München
}

\section{INTRODUCCIÓN: LA DISTRACCIÓN DEL PENSAR}

Dice Malebranche que el hombre antes de su pecado no era el esclavo, sino el señor absoluto de sus pasiones (N. Malebranche, 1967: V, I, t. II, p. 130). En aquel estado plenamente gozoso no habría nada que echara en falta: ninguna atracción irresistible, ninguna fascinación invencible. Pero nadie es más débil ante la promesa de lo desconocido que el señor absoluto de sus pasiones que todo lo conoce, porque donde el conocimiento no echa nada en falta, la mera promesa de un umbral de novedades desconocido, aunque no muestre ningún objeto nuevo de conocimiento, sino confusas imágines, despierta el poder de la imaginación, la reina de las facultades (C. Baudelaire, 1956: III, p. 773), que atraída por la promesa de una novedad meramente imaginada (de una vaguedad tan oscura como fascinante) distrae a la razón del sosiego de la lógica hacia un ámbito donde en sentido propio no hay nada que conocer salvo, eso sí, a sî misma alienada y en un posterior calvario de redención hacia lo pensable.

No creo que quepa indicar algo más débil ante la promesa de lo desconocido, que el espíritu que todo lo conoce. Movido por el deseo promovido por la imaginación, la libertad se desvanece: la inteligencia pierde su autodominio; pierde aquel estado de calma imperturbable que la embarga cuando apaciblemente contempla la posibilidad total de todo lo pensable (logos sin pasiones). Al margen de la lógica, la Idea fuera de sí (extrañada y alienada) se distrae ejerciéndose allí donde su poder patina incapaz de lograr el mínimo concepto.

Lógicamente, no hay ninguna necesidad de que las cosas sean necesariamente de este modo, pero poco se podría hacer frente a esta posibilidad. Pues aunque ciertamente no hay ninguna razón para que se dé tal distracción, e incluso habría que decir que tal distracción es irracional, ocurre sin embargo que allí donde se promete una región donde la lógica no alcanza, brota el deseo irrefrenable de la razón movida fatalistamente más allá de lo pensable. Pero no se trata ya de afirmar que la razón sucumbe fácilmente a la tentación de abandonar sus límites en el sentido de funcionar al margen de la imaginación, 
como había dicho Kant, sino la inversa: lo que la razón debe evitar es enredarse en los asuntos de la imaginación, y ejercerse pura, sin distracciones

"Indem auf diese Weise die Wirklichkeit alle Substantialität verloren [hat] und nichts mehr an sich in ihr ist, so ist wie das Reich des Glaubens, so auch das der realen Welt gestürzt, und diese Revolution bringt die absolute Freiheit hervor, womit der vorher entfremdete Geist vollkommen in sich zurückgegangen ist, dies Land der Bildung verläßt und in ein anderes Land, in das Land des moralischen Bewußtseins übergeht” (G. W. F. Hegel, 1976: III, p. 361)

aunque le cueste un calvario

"Das Ziel, das absolute Wissen, oder der sich als Geist wissende Geist hat zu seinem Wege die Erinnerung der Geister, wie sie an ihnen selbst sind und die Organisation ihres Reichs vollbringen. Ihre Aufbewahrung nach der Seite ihres freien, in der Form der Zufälligkeit erscheinenden Daseins ist die Geschichte, nach der Seite ihrer begriffenen Organisation aber die Wissenschaft des erscheinenden Wissens; beide zusammen, die begriffene Geschichte, bilden die Erinnerung und die Schädelstätte des absoluten Geistes, die Wirklichkeit, Wahrheit und Gewißheit seines Throns, ohne den er das leblose Einsame wäre" (Ibidem, p. 590).

Pero sea como fuere, aquí se sigue hablando de límites. Los límites del conocimiento son fácilmente rebasados por la voluntad. Ya había hablado Descartes de la amplitudo voluntatis, pero creo que nadie como Hegel, y quizás porque el alemán había conocido la consolidación de la tesis empirista según la cual las ideas metafísicas son obras de la imaginación, ha puesto tanto hincapié en delimitar los límites del saber frente al criterio empirista de sentido. La historia del pensar descrita por Hegel consiste en pensar todo lo pensable, donde este todo lo pensable tiene el sentido de "sólo lo pensable" a lo que debemos volver después de que el pensar se ha distraído de su tema movido irracionalmente fuera de su elemento racional.

La tarea de la historia del pensar es así, la tarea de liberarse de la distracción. Una tarea que es, enunciada en otros términos, la tarea de liberarse de la imaginación que el empirismo inglés había enredado en las cuestiones metafísicas, y que como todo buen lector de Platón sabe, esto es tanto como haber metido al enemigo en casa.

\section{El iDEALISMo y los LÍMITES Del Conocimiento}

La imaginación es la facultad que nos entrega un reino donde todo parece estar a nuestro alcance. Un porvenir ilusorio, creado y generado por la facultad, pero suficientemente atractivo como para distraer a una razón sosegada en la contemplación de todo lo pensable, atraída por ese más allá de todo lo pensable. Alienada por un reino tan prometedor como ilusorio (un reino que nunca 
devendrá como había sido imaginado), no tardará en revelarse aquella "señora del mundo" (N. Malebranche, 1978: VI, p. 272), después de haber arrastrado al pensar, como "maestra del error y de falsedad (...) que parece sernos dada adrede para inducirnos a un error necesario..." (B. Pascal, 1960: frag. 82.

Lo real es lo lógicamente pensable, tal es la afirmación idealista, que se opone a toda deriva irracional de la confusa y liante imaginación. Un idealista nunca cedería ante las proyecciones imaginativas cuyas promesas son sólo ilusorias, antes bien y muy al contrario, se aferrará a lo lógicamente pensable que es al mismo tiempo y en el mismo sentido lo único real. No es Hegel, en menor medida que Hume o Locke, un crítico de todo traspasar los límites de lo pensable. Pero para Hegel, y aquí está el desacuerdo con el empirismo, las ideas metafísicas no están más allá de esos límites.

Hume nunca negó que hubiera conocimiento en las relaciones de ideas (juicios analíticos), pero pensaba que suerte distinta corría en las cuestiones de hecho, porque allí la verdad no era lógica, y se afirmaba más allá (imaginación) de lo que debía afirmarse. En esta misma línea el atomismo lógico de Russel y el primer Wittgenstein intentarán ofrecer la lógica correcta. Pero contra, Hegel no hace una lógica desde la base del empirismo, sino que quiere rectificar a Hume en este punto principal: dándole la razón en que sólo cabe necesidad en la lógica, la afirmación idealista es que el saber absoluto es eso mismo, lógica; y la metafísica, por ello mismo, no imagina nada a partir de lo particular, sino que se mueve en el elemento racional donde lo lógico es pensable.

Así, en la Ciencia de la lógica la cantidad y la cualidad están incluidas tanto como su síntesis que es la medida, pero en la jerarquía hacia la Idea absoluta la diferencia esencial, por ejemplo, o la razón de ser son estadios posteriores y superiores, y nunca menos lógicas. ¿Es que acaso no es lógico pensar que allí donde hay una pluralidad de medidas surge el conocimiento de la diferencia esencial como opuesto a la identidad de la esencia, quiero decir, no resulta que allí donde se mide la altura, la velocidad, los caballos... cabe, a pesar de estas diferencias, decir coche aún cuando no sepamos todavía qué es lo que hace a cada coche un coche

"Der Grund ist die Einheit der Identität und des Unterschiedes; die Wahrheit dessen, als was sich der Unterschied und die Identität ergeben hat, - die Reflexionin-sich, die ebensosehr Reflexion-in-Anderes und umgekehrt ist. Er ist das Wesen als Totalität gesetzt" G. W. F. Hegel, Werke in zwanzig Bänden, 1977: VIII, pp. 246-247)

En el mismo plano lógico desde el que las matemáticas gozan de prestigio cabe seguir avanzado (una exigencia lógica) porque con la idea de medida no se ha agotado todo lo lógicamente pensable. Pero este más allá es un profundizar en la lógica y por ende en el conocimiento necesario. Allí donde Hume 
observa un abandono de la lógica y las relaciones de ideas, Hegel observa un mayor ahondamiento en lo lógico según un método que es pura relación de ideas: la dialéctica.

Aceptado el envite del empirismo, Hegel asume que sólo hay verdad en la lógica, pero rechaza que las cuestiones filosóficas y trascendentales estén fuera de dicho ámbito. Y por supuesto, nada hay real fuera de la lógica, pues pensar que hay un afuera ha sido la ilusión de la imaginación. Así se produce la vuelta respecto de la tesis empirista: ideas como la idea de sustancia no son menos reales por carecer de impresión correspondiente, sino que siendo sólo lógicas son auténticamente reales; siendo el reino de la mentira y de la falsedad el de la impresión que se mueve entre imágenes que no llevan a ningún objeto de conocimiento. Del mismo modo que el rostro reflejado en el espejo distrae al observador y le impide concentrarse en lo auténticamente importante (la mirada), ocurre también que el pensar se distrae con las imágenes y no se concentra en lo relevante, el pensar.

Para Hegel, como en su momento dijo Platón, las ideas filosóficas son las únicas verdaderas porque no son imaginadas, sino lógicamente pensadas, y están lejos del espectro que genera opinión y confusión. Lo que no acepta un idealista, por amor a las ideas, es que se otorgue a la imaginación un lugar privilegiado en el juicio científico tal y como Kant habría establecido, (seguramente a su pesar [por ello Kant anula, haciendo desaparecer la imaginación trascendental, el privilegio del tiempo en la formación de la trascendencia como tal, lo que equivale a negar la pieza principal de la fundamentación de la metafísica según ha expuesto Heidegger en su Kant y el problema de la fundamentación de la metafísica], y por eso rectificó en su segunda edición), en la Crítica de la razón pura. Dicho en pocas palabras: lo más contrario al idealismo hegeliano es un soñador que se deja llevar por sus ilusiones. En la vida cotidiana, un idealista auténtico sería reconocido entre sus paisanos como aquel hombre realista que no se deja enredar en planes irrealizables y poco lógicos.

\section{IMAGINACIÓN SIN IMÁGENES}

Debería indicarse por otro lado que cuando Kant recurre a la imaginación, lo hace aludiendo a un tipo de imaginación que no proyecta imágenes, sino que ofrece esquemas. Algo así como si nos preguntáramos ¿cuál es la imagen que corresponde a la figura engendrada por tres rectas que se cortan mutuamente? El triángulo. Pero este triángulo carece de una forma y dimensión determinada. No es ni recto, ni isósceles, ni equilátero, ni escaleno. No tiene tamaño, ni color... lo imaginamos sin llegar a formar una imagen. Su determinación particular es una pura significación, una indicación de sentido a la que ninguna imagen particular le corresponde. Al triángulo le ocurre, al menos según la filosofía cartesiana, como a Dios: ese ser infinito que podemos pensar con total claridad, 
pero que no podemos entender. Algo parecido acontece también cuando intentamos imaginar una montaña sin valle, de esas que un voluntarista medieval consideraba que Dios podía hacer si quería, por más que le sea imposible a cualquier voluntarista una representación semejante. También la noción de hombre liberado de la sociedad (como habían imaginado monjes y marxistas), pues a este hombre no le podemos poner rostro ni manos: pues no son iguales los ojos de minero o de cirujano, ni las manos de violinista o de campesino. Esta imaginación sin imagen está, según Kant, en la base del conocimiento científicamente verdadero, pues a sus esquemas debe el conocimiento teórico la posibilidad de unir intuiciones y conceptos, sin la cual quedarían respectivamente ciegas y vacíos.

La imaginación en la base de los juicios sintéticos a priori, había sido la solución kantiana para evitar el escepticismo de la filosofía de Hume. La imaginación en la base de los enunciados aceptables no es, por supuesto, algo descabellado. Se puede plantear si la creencia en la existencia de un universo externo que no depende de nuestra percepción (y que existiría aunque nosotros, y toda criatura sensible, estuviéramos ausentes o hubiéramos sido aniquilados

\begin{abstract}
"It seems also evident, that, when men follow this blind and powerful instinct of nature, they always suppose the very images, presented by the senses, to be the external objects, and never entertain any suspicion, that the one are nothing but representations of the other. This very table which we see white, and which we feel hard, is believed to exist, independent of our perception, and to be something external to our mind, which perceives it. Our presence bestows not being on it: our absence does not annihilate it. It preserves its existence uniform and entire, independent of the situation of intelligent beings, who perceive or contemplate it" D. Hume, 1978: 12, 1])
\end{abstract}

se funda en la imaginación. Pero el idealismo rectifica esta consideración diciendo que no es la imaginación, sino la lógica la que da este paso.

Aunque la versión liviana de la imaginación sigue gobernando la razón, debe observarse sin embargo el intento kantiano de, en la Crítica de la razón práctica, intentar mostrar que el ir más allá de aquellos límites del entendimiento es una inclinación natural de la razón por la que ésta no deja de ser menos racional. Dicho abandono se hace inclinados por la observación de una estricta necesariedad lógica ( $a l s o b$ ) que se prosigue según una determinada ley formal (imperativo de la racionalidad del querer) que es una exigencia categórica a la autonomía de la razón (libertad). Este Kant, el de la Crítica de la razón práctica es el que inicia el idealismo alemán, que propiamente sobreviene al intentar afirmar también para el conocimiento teórico esta misma autonomía (Fichte). 
Lo cual también podría presentarse de este otro modo: puestos a detectar los límites del entendimiento posible, quizás lo más atrevido sea plantearlo a la inversa del empirismo: la sensibilidad como límite no en el sentido de más allá de ella no, sino en el sentido de sólo al margen de ella. Y ello, proponiendo otro método cognoscitivo a partir del cual sea posible pensar las cosas de una manera más racional y menos apegada a las impresiones: el hecho de que con la imaginación no se puedan conocer universales, para el idealismo sólo significa que el pensar debe proceder de otros modos si quiere llegar a saber algo. Y este otro modo es la lógica. O, en palabras de Heidegger, la "lógica filosofante" (Cfr, M. Heidegger: 1995, § 3). En la línea en que Platón había dicho que era necesaria cierta técnica dialéctica para ir abandonando el estadio de las imágenes sombrías hasta alcanzar el estadio de la episteme donde cabe hablar propiamente de conocimiento.

Si bien, Hegel es aún más radical que Platón. No es ya sólo que la imaginación sea el más pobre de los niveles cognoscitivos, sino que por su vaguedad, ni siquiera debería considerársele un nivel cognoscitivo. Sólo lo lógico es todo lo pensable. Los objetos de la imaginación no son pensables, sino indeterminados e ilusorios... no son realmente objetos de conocimiento. Hegel sabe que la tarea no es fácil, que hay un largo calvario del espíritu por delante. Distraído entre fenómenos, esforzándose inútilmente en los hechos, nada llega a saberse, ningún concepto es capaz de elaborarse... hasta que se descubre el pensar así mismo en el fenómeno, tomando conciencia de que el asunto del conocimiento es el propio pensar (autoconciencia) y puede emprenderse así la ciencia de la experiencia de la conciencia; proceso en el que el espíritu va librándose de todo lo exterior y concentrándose cada vez más en sí mismo hasta contemplar sólo todo lo pensable que es lo único pensable y real.

\section{LA IMAGINACIÓN EN EL ENFOQUE CLÁSICO}

Al prescindir de la imaginación, se desvanece todo contacto con la realidad. Tanto idealismo como empirismo comparten una idea común: la imaginación es el límite de la razón. Ambas posturas parten de que la imaginación no produce ningún objeto de conocimiento. La diferencia va a estar más bien en sostener que todo conocimiento sobre el mundo que vaya más allá de la impresión correspondiente es una idea ficta o en desvincular a la lógica y la ciencia de la imaginación. Pero en ambos casos el resultado va a ser parcialmente el mismo: el desvanecimiento de la realidad exterior, desvanecimiento que el empirismo lleva a cabo bajo la forma del escepticismo consecuente y el idealismo lleva a cabo, por su parte, bajo la forma de la consumación del escepticismo en tanto que la skepsis es la mirada que llega a descubrir, desde la actitud negativa respecto a toda objetivización, la propia actividad pensante como auténtico asunto del conocimiento cuya tarea no está encomendada a la imaginación. 
Dicho en pocas palabras podríamos presentar el empirismo y el idealismo del siguiente modo:

a. El empirismo es aquella corriente filosófica que sostiene que el límite del conocimiento es la sensibilidad en el sentido de que no se puede ir más allá de ella sin rebasar su uso legítimo.

b. El idealismo es aquella corriente filosófica que responde al empirismo diciendo: el límite del conocimiento es la sensibilidad en el sentido de que no se puede conocer lo sensible porque, en sentido estricto, no hay nada que conocer, y se debe a la imaginación la distracción de la razón en tales asuntos.

Por supuesto, detectar la sensibilidad como límite es un asunto clásico. Aunque esta dualidad en litigio ha tenido distintas formulaciones: lo extenso y lo pensante, lo material y lo espiritual, lo activo y lo pasivo (Cfr., J. Arana, 2005: p. 18). Pero todas estas formulaciones, como sabe Kant, responden al problema clásico de la dualidad sensibilidad-inteligencia.

Si bien, hay dos distinciones bien interesantes entre el enfoque clásico y el empirismo y el idealismo:

1. El enfoque clásico, frente al empirismo, sostiene que hay una jerarquía intelectual dentro de la cual la imaginación se distingue de la razón.

2. Frente al idealismo sostiene cierta dependencia de la razón respecto de la imaginación según el siguiente sentido: para que haya objeto en la inteligencia, hace falta que exista primero una especie impresa (Cfr., L. Polo, 2009: p. 216) que le sea dada a la inteligencia (el abstracto, que el intelecto agente logra iluminando la especie expresa de la fantasía: imaginación como motus factus a sensu secundum actum (Cfr. De anima, 1. II al final y 1. III, al inicio)).

El problema del enfoque clásico, por su parte, es que en la medida en que sostiene, por analogía, que la inteligencia requiere que le sea otorgada una especie impresa, resulta una concepción de la inteligencia volcada hacia el exterior (al conocimiento de la realidad) que, aunque frente al empirismo y al idealismo tiene la virtud de hacerlo posible, arrastra el impedimento de no conceder como asunto del pensar el pensar mismo.

Pero entiendo que la cuestión sería bien distinta si se sustituyera el par sensibilidad-inteligencia por el par presencia-oculto, que es un intento propiamente fenomenológico (Es paradigmático el modo como Heidegger los versículos 6-9 del capítulo 10 del libro 9 de la Metafísica de Aristóteles:

"Nicht nämlich auf Grund davon, daß wir entdeckend dich nehmen in deinem Vorhandensein als weiß, bist du wieß, sondern auf dem Grunde deines Vorhandenseins als wieß $-d$. i. sofern wir dieses Vorhandene im Reden sehen Lassen, verhalten wir uns entdeckend" (M. Heidegger, 1995: p. 175) 
y que tiene la virtud de mostrar que lo que la inteligencia necesita para operar no es una especie impresa, sino una presencia (La tesis de Husserl es ego cogito cogitatum: afirmar el polo subjetivo del fenómeno (cogitatum) - mis cogitationes variables (ego) - es afirmar la síntesis noético-noemática, la unidad de una objetividad intencional que consiste, a fin de cuentas, en una Vergegenwärtigung (presentificación)).

\section{LA PRESENCIA COMO LÍMITE DE LA LÓGICA}

Siguiendo la alternativa aludida, resultaría entonces que el límite del conocimiento no se dirimiría entre sensibilidad o inteligencia, sino en la posibilidad o no posibilidad de pensar más allá de la presencia. Lo cual en sentido estricto la fenomenología no pretende (ni siquiera Heidegger [Ciertamente no cabe acusar a Heidegger de presencialista porque su asunto no se hace presente. Pero es un logocentrista, y tiene razón Derridá, porque intenta pensar eso no presente sin abandonar la presencia, lo que significaría, de entrada, prescindir de las imágenes y símbolos (para los empiristas, Heidegger ha transgredido los límites del conocimiento, y para los idealistas Heidegger ha abandonado la lógica)]), porque para la fenomenología la presencia es temporal, y ese más allá de la presencia sólo puede buscarse si se piensa como la característica de nuestro conocimiento intencional.

La fenomenología no se propone la posibilidad de dicho abandono, pero en principio es posible pensar en una teoría del conocimiento que defendiera lo contrario ("la presencia es presencia mental, no temporal; es decir, es presencia a..., al cognoscente, tanto o más que presencia de..., de lo conocido. El presente temporal remite, pues, al acto de conocimiento, un acto que posee inmanentemente su fin, y que es externo al devenir de los procesos materiales. Precisamente por ser externo y articular desde fuera el curso del tiempo, cabe proponer el abandono de la presencia para conocer el ser extramental" J. A. García, 2006: p. 81) promoviendo el análisis metódico del pensar decidido a estudiar la actividad pensante como orientación hacia una meta que es sólo y siempre meta (Cfr, I. Falgueras, 1976: p. 302), de modo que se pudiera pensar y entender dicha orientación, y a partir de aquí, abandonar la solidaridad metódico-temática (la congruencia) para pensar no sólo el tema sin método (la realidad en tanto que no presente), sino también y muy especialmente el método sin tema -método como tema-: el intellectus en tanto que actividad independiente del fundamento; lo que sería, en un sentido propiamente estricto, la pura actividad pensante en tanto que tal actividad. 


\section{REFERENCIAS}

Arana, J., 2005: Los filósofos y la libertad, Madrid: Síntesis

Aristóteles, 1831: Aristotelis Opera, Berlín: G. Reimer

Baudelaire, Ch., 1956: Ouvres complètes, París: Bibliothèque de la Pléiade

Falgueras, I., 1976: La res cogitans en Espinosa, Pamplona: EUNSA

García, J.A., 2006: Después de Husserl, Buenos Aires: Librosenred

Hegel, G. W. F., 1970: E. Modelnhauer y K. M. Michel (eds), Hegel Werke in zwanzig Bänden, Frankfurt: Suhrkamp

Heidegger, M., 1955: Logik. Die Frage nach Der Wahrheit, Frankfurt: Klostermann

Hume, D., 1978: P.D. Nidditch (ed), Oxford: Clarendon Press

Malebranche, N., 1967: J. Vrin y CNRS (eds), Oeuvres complètes, París: Vrin

Pascal, B., 1960: Ouvres complètes, París: Seuil

Polo, L., 2009: Lecciones de psicología clásica, Pamplona: EUNSA 
